\title{
O trabalho com a ortografia no gênero Anúncio Publicitário
}

\author{
El trabajo con la ortografía en el género Anuncio Publicitario \\ The work with orthography in the advertisement genre
}

\author{
Ms. Nadieli Mara Hullen Gerei ${ }^{1}$
}

\begin{abstract}
Resumo
Neste trabalho apresentaremos resultados parciais de pesquisa de Mestrado intitulada "Desvios de grafia em produções textuais escritas de alunos do $6^{\circ}$ ano do Ensino Fundamental". Para a realização da pesquisa, fizemos uma coleta inicial de textos, do gênero autobiografia, e dividimos os desvios de grafia encontrados nas produções de acordo com categorias estabelecidas por Bortoni-Ricardo (2006). Em seguida, desenvolvemos e aplicamos uma Unidade Didática, com o objetivo de fazer com que esses desvios diminuíssem ou, até, fossem eliminados. Ao final da Unidade, como proposta de produção textual, solicitamos que os alunos criassem anúncios publicitários. Esse gênero foi escolhido devido a sua expressiva circulação na sociedade, sendo, assim, comum ao cotidiano dos alunos, e também por favorecer uma percepção da linguagem em uso. Como base teórica, nos baseamos principalmente em Carvalho (2009) e Sandmann (2010). É uma pesquisa que se situa nas áreas da Linguística Aplicada e da Sociologia da Linguagem, com o aporte metodológico da Sociolinguística Variacionista. Como as produções dos anúncios publicitários, foi possível perceber que o trabalho com a ortografia gerou resultados positivos, tendo a vista a diminuição e eliminação dos desvios.
\end{abstract}

Palavras-Chave: Ensino, Ortografia, Variação Linguística.

\section{Resumen}

En este trabajo presentaremos los resultados parciales de la pesquisa para el grado de Maestría intitulada "Desvíos de grafía en producciones textuales escritas de alumnos del $6^{\circ}$ grado de la Enseñanza Fundamental". Para la realización de la pesquisa, hicimos una colección inicial de textos, del género autobiografía y dividimos los desvíos de grafías encontrados en las producciones de acuerdo con las categorías establecidas por BortoniRicardo (2006). A continuación, desarrollamos y aplicamos una Unidad Didáctica, con el objetivo de hacer con que estos desvíos disminuyesen o incluso fueran eliminados. Al final de la Unidad, como propuesta de producción textual, pedimos a los alumnos para crear sus anuncios publicitarios. Este género fue elegido debido a su expresiva circulación en la sociedad, siendo, así común al cotidiano de los alumnos y también por fomentar una percepción del lenguaje en uso. Como base teórica, nos basamos principalmente en Carvalho (2009) e Sandmann (2010). Es una pesquisa situada en las áreas de Lingüística Aplicada y de la Sociología del Lenguaje, con el aporte teórico de la Sociolingüística Variacionista. Las producciones de los anuncios publicitarios, reveló que el trabajo con la ortografía resultó positivo, pues hubo la disminución y eliminación de los desvíos.

Palabras-clave: Enseñanza; Ortografía; Variación Lingüística.

\begin{abstract}
In this work we will present some partial results of the Master research entitled "Writing deviation in the written production of students from the $6^{\circ}$ grade of the Fundamental School. In order to do the research, we have made an initial collection of texts, from the autobiography genre, and we have divided the writing deviations we found in them according to the categories which were established by Bortoni-Ricardo (2006). Then, we have developed and applied a Didactic Unit, with the intention of making these deviations to diminish or, also, to be eliminated. By the end of the Unit, as a textual production proposal, we asked the students to create some advertisements. This genre was selected because of its great use on our society, being, this way, common to the students' routine, and also for favoring to a perception of the language in use. As the theoretical basis, this work is specially based in Carvalho (2009) and Sandmann (2010). It is a research which stands on the Applied Linguistics and the
\end{abstract}

\footnotetext{
1 (Mestre em Letras; UNIOESTE - Universidade Estadual do Oeste do Paraná; Cascavel, Paraná, Brasil; nadielimara@hotmail.com).
} 
Sociology of Language Fields, with the methodological contribution of the Variationist Sociolinguistics. With the advertisement production, it was possible to realize that the work with the orthography has had positive results, considering the diminishment and the elimination of the deviations.

Keywords: Education, Orthography, Linguistic Variation.

\section{Contextualização}

Esta pesquisa foi realizada em um colégio campo do Programa Institucional de Bolsas de Iniciação à Docência (PIBID), do Subprojeto de Língua Portuguesa, no qual atuei durante três anos como bolsista e hoje atuo como pesquisadora voluntária. O recorte de escolaridade para a pesquisa foi o $6^{\circ}$ ano, pois prevê-se que, nesta fase, o aluno já tenha superado a etapa de testagem de hipóteses sobre a organização da escrita e tenha desenvolvido a consciência e a percepção sobre a fala e a escrita.

Conhecer o código escrito e suas irregularidades é um dos desafios que os alunos enfrentam na escola, considerando-se as convenções do código ortográfico e a influência da fala. Sabemos, e devemos repassar aos alunos, que a escolha de uma grafia para as palavras foi necessária, pois precisamos nos entender, de norte a sul do país, sem as interferências das variedades linguísticas. Para fazer esta escolha, fez-se uma seleção, que recaiu, obviamente, na variante usada pela classe dominante. Com essa seleção, houve também uma exclusão dos demais usos, que implicou em estigmatização daquilo que não pertencia à elite.

Para fazer este seleto grupo de normas circular na sociedade, a escola foi o principal meio de propagação. Paralelamente, as variantes continuaram a existir, o que resultou em um grande distanciamento entre ambas, norma-padrão e variantes. A norma-padrão se constituiu assim, como uma ferramenta de exclusão e de repressão, fazendo a maioria dos brasileiros acreditar que não sabe falar e escrever, equívoco que é reforçado constantemente pela mídia e por alguns professores.

$\mathrm{Na}$ escola, o principal trabalho dos professores, principalmente os de Língua Portuguesa, pauta-se na uniformização da escrita a partir da ortografia estabelecida. Porém, muitas vezes, os alunos cometem desvios ortográficos que ficam sem explicação, pela dificuldade de os professores entenderem a natureza das diferentes formas de grafias utilizadas nas produções escritas. Então, mostram-se necessárias pesquisas para entendermos o desvio, analisá-lo, além elaborarmos estratégias para sua eliminação.

Segundo Morais (2007), o aprendizado desta ortografia não é algo que se faz passivamente e com simples técnicas de memorização, pois os próprios desvios ortográficos cometidos pelos alunos revelam regularidades; estas podem ser observadas quando o aluno 
escreve uma palavra de outra forma que poderia ser possível em língua portuguesa (por exemplo, "caza" para “casa").

Ainda, segundo o autor, o aluno reelabora mentalmente as informações que recebe, e é papel da escola auxiliá-lo neste processo. Para que isto ocorra, é fundamental que, em primeiro lugar, o professor saiba o que é regular e o que é irregular na língua, para depois auxiliar o aluno. De acordo com Morais (2007), "quando se aprende sobre ortografia a partir da reflexão, sempre há o que descobrir" (MORAIS, 2007, p. 96).

Outro conhecimento que deve ser construído com os alunos é o de que a fala é condicionada por fatores como a classe social, a região geográfica - que por sua vez sofre interferências de acordo com sua história e colonização - a comunidade de onde vêm, entre outros. Porém, na escrita, devemos seguir um padrão para que sejamos compreendidos pelas pessoas de nosso ou de outro contexto social.

De acordo com Busse, "na atividade de escrita o aluno toma a fala como ponto de partida, registrando as variantes da sua comunidade de fala ou transcrevendo-a a partir do seu contínuo" (BUSSE, 2013, p. 196). Desta maneira, na escola, o estudante deve começar a compreender a distinção entre a fala e a escrita. Enquanto não faz essa distinção, muitos traços típicos da fala aparecem em seu texto.

Para a pesquisadora, o primeiro passo para a inserção efetiva do aluno no mundo letrado, marcado pelas diversidades linguísticas, é o amplo conhecimento e respeito por parte do professor referente à heterogeneidade linguística do grupo. Se o professor não tiver conhecimento sobre a fonética e a fonologia da língua, não conseguirá compreender porque seus alunos comentem determinados desvios de registro, e, consequentemente, não respeitará as diversidades linguísticas presentes na sala de aula.

Segundo Busse,
Além do percurso escolar, o aluno deve compreender a organização da língua como um fenômeno social, histórico e geográfico. Essa complexa constituição imprime à língua em uso a realidade do falante. Na escola, contudo, o aluno deve lidar com o exercício da abstração e compreender a regularidade da escrita. Esse processo que está diretamente ligado à aprendizagem da escrita requer um acompanhamento sistemático do professor (BUSSE, 2013, p. 192).

Além dessas interferências da fala na escrita, desvios provenientes da arbitrariedade do código escrito também são possíveis de ocorrer, como um mesmo som que pode ser representado por diversas letras, por exemplo a sibilante /s/. Lemle (1993) destaca que esse problema só será sanado quando o aluno decorar as estruturas, sendo a última etapa que o 
aluno atingirá; caberia acrescentar aqui que acreditamos ser a leitura o caminho mais fácil, rápido e eficiente para se chegar a essa fixação da estrutura das palavras.

Por procurarmos seguir as metodologias e concepções descritas, fizemos uma geração inicial de textos, do gênero autobiografia, que foram encaminhadas pela professora de Língua Portuguesa da turma. Após esta geração, foi feito um levantamento dos desvios de grafia, de acordo com as categorizações feitas por Bortoni-Ricardo (2006), conforme apresentaremos na Metodologia.

Percebemos, nesses textos, se os problemas de grafia eram predominantemente relacionados à fala e suas interferências na escrita ou se eram maiormente próximos à arbitrariedade do código. De acordo com os resultados que obtivemos, realizamos uma Unidade Didática, com o gênero anúncio publicitário, para trabalharmos as dificuldades dos alunos.

Para a análise dos dados gerados nos textos do gênero anúncio publicitário, utilizamos as mesmas categorias da análise dos textos do gênero autobiografia, que serão explicadas na Metodologia.

\section{Objetivos}

Nossos objetivos, com esta pesquisa, com a aplicação da Unidade Didática e com a produção textual do gênero anúncio publicitário, foram os de levar os alunos a compreenderem as regularidades e as irregularidades ortográficas da língua portuguesa; a reconhecerem as representações grafemáticas de uma mesma unidade sonora e a identificarem as principais características e elementos do gênero anúncio publicitário.

\section{Metodologia}

Para atingirmos nossos objetivos, nossa metodologia foi composta por atividades como: banco de palavras; análise das características do gênero anúncio publicitário; produção de regras a respeito do uso de determinadas letras para representar um som; audição de músicas e registro de palavras específicas da canção; organização das palavras em grupos, conforme as suas semelhanças; confecção de listas de palavras utilizando alguma semelhança entre estas; realização de atividades de escrita e promoção da escrita espontânea.

As atividades aplicadas tiveram como conteúdos a ortografia e a produção textual, sendo conteúdos estruturantes a análise linguística e a ortografia. 
Os conteúdos específicos trabalhados na Unidade Didática foram a representação grafemática das sibilantes surdas e sonoras /s/ e /z/; /g/ e /j/; /x/ e /ch/ e a conjugação de verbos no pretérito na $3^{\mathrm{a}}$ pessoa do plural /am/ e no futuro do indicativo na $3^{\mathrm{a}}$ pessoa do plural /ão/.

A produção do anúncio foi feita para percebermos e avaliarmos de que forma e em que medida as atividades mais direcionadas para a reflexão linguística, em especial a ortografia, podem colaborar para a diminuição dos desvios percebidos na produção textual autobiografia.

Para a produção textual, levamos aos alunos alguns produtos de beleza que pertenciam à pesquisadora, para que lessem, reconhecessem a marca e tivessem um material para se inspirarem na produção. Não era obrigatório que fossem utilizados estes produtos, os alunos poderiam criar um anúncio para qualquer produto existente na sociedade ou um produto que fosse fruto de sua imaginação.

Para a análise dos desvios encontrados, conforme exposto na Contextualização, no baseamos nas categorias que Bortoni-Ricardo (2006) estabelece. São elas: 1) Problemas decorrentes da própria natureza arbitrária da língua - onde alocamos os problemas de representação nasal e de representação da sibilante. A segunda categoria, na qual estão os problemas decorrentes da transposição dos hábitos da fala para a escrita, é dividida em três partes: 2.1) Problemas decorrentes da interferência de regras fonológicas no falar estudado; 2.2) Problemas decorrentes da interferência de regras fonológicas variáveis graduais e 2.3) Problemas decorrentes da interferência de regras fonológicas variáveis descontínuas.

\section{Resultados}

Após a coleta das produções textuais anúncios publicitários, analisamos os desvios encontrados no anúncio publicitário:

Quadro 01: Desvios provenientes da natureza arbitrária da língua e hipercorreção em textos de meninos:

\section{Desvios decorrentes da própria natureza arbitrária da língua.}

\begin{tabular}{l|l|l|}
\multicolumn{1}{|c|}{ Arbitrariedades do código } & Hipercorreção \\
\hline Linpeza & \\
En & \\
Fasa & \\
Esprementaram &
\end{tabular}

Fonte: Produção de texto anúncio publicitário. Realizada em 09/11/2016 e 22/11/2016. 
Nos anúncios publicitários produzidos dos meninos, tivemos dois desvios de representação nasal, nas palavras "linpeza" (limpeza) e "en" (em) e dois desvios de representação da sibilante /s/, nas palavras "fasa" (faça) e "esprementaram" (experimentaram).

No quadro 02, na sequência, veremos os desvios provenientes da transposição da fala para a escrita em textos de meninos.

Quadro 02: Desvios provenientes da transposição da fala para a escrita em textos de meninos:

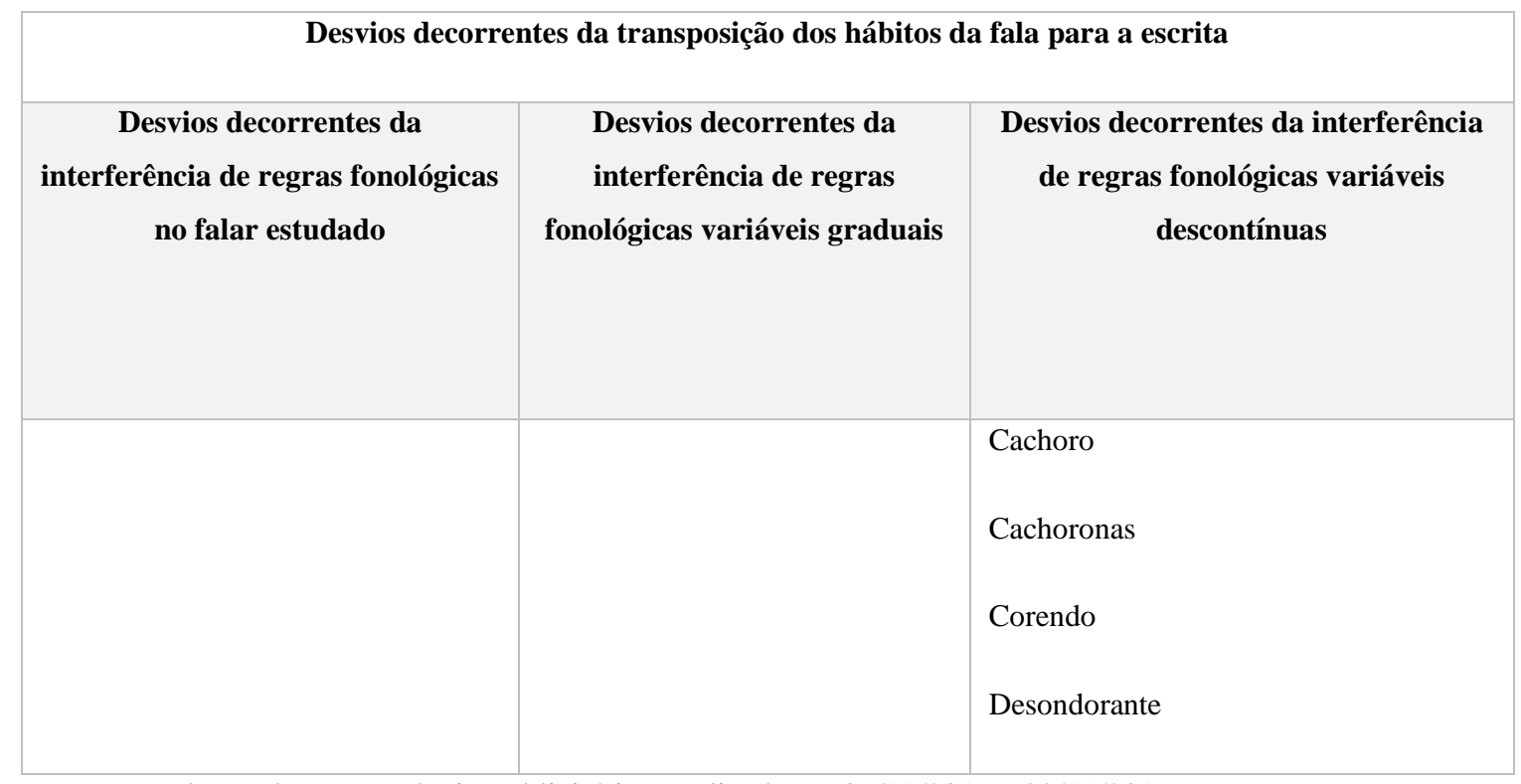

Fonte: Produção de texto anúncio publicitário. Realizada em 09/11/2016 e 22/11/2016.

Nos desvios decorrentes da transposição dos hábitos da fala para a escrita, encontramos três palavras que classificamos na categoria desvios decorrentes da interferência de regras fonológicas descontínuas, que são "cachoro" (cachorro), "cachorona" (cachorrona) e "corendo" (correndo). Nas três, percebemos que o aluno utiliza o/r/ tepe ao invés do vibrante ou do velar; considerando a história de colonização do Oeste do Paraná, predominantemente por italianos e alemães, e sabendo que em suas línguas de origem o /r/ tepe é o mais utilizado, inclusive em início de palavra ou de /r/ duplo em meio de palavra, podemos inferir que, provavelmente, o aluno sofre desta influência.

Nesta categoria incluímos também a palavra "desondorante" (desodorante), pois, para nós, parece um caso de nasalização, como na palavra "indentidade" (identidade). Embora Bortoni-Ricardo (2006) não classifique explicitamente a nasalização nessa categoria, sabemos que essa nasalização também é um marcador de um grupo social, proveniente da região rural, fator previsto para essa categoria. 
Algumas palavras, encontradas no corpus, não conseguimos classificar em nenhuma das categorias estabelecidas por Bortoni-Ricardo (2006). São elas: "refrecante" (refrescante) e "greme" (creme). Então, recorremos à classificação de Oliveira (2005), que criou uma categoria específica para esses desvios de escrita, o G3B, que ele chama de "outros casos e casos acidentais".

A seguir, apresentamos o quadro 03, desvios provenientes da natureza arbitrária da língua.

Quadro 03: Desvios provenientes da natureza arbitrária da língua em textos de meninas:

\begin{tabular}{|l|l|}
\hline \multicolumn{2}{|c|}{ Desvios decorrentes da própria natureza arbitrária da língua } \\
\hline \multicolumn{1}{|c|}{ Arbitrariedades do código } & Hipercorreção \\
\hline Um & \\
Comese & \\
Toms & \\
\hline
\end{tabular}

Fonte: Produção de texto anúncio publicitário. Realizada em 09/11/2016 e 22/11/2016.

No caso das meninas, em relação às arbitrariedades do código, tivemos dois desvios de representação nasal, nas palavras "un" (um) e "toms" (tons) e um desvio de representação da sibilante /s/, na palavra "comese" (comece). Também tivemos um caso de hipercorreção, na palavra "macil" (macio).

A seguir, no quadro 04, apresentamos desvios provenientes da transposição dos hábitos da fala para a escrita.

Quadro 04: Desvios provenientes da transposição dos hábitos da fala para a escrita em textos de meninas:

\begin{tabular}{|c|c|c|}
\hline \multicolumn{3}{|c|}{ Desvios decorrentes da transposição dos hábitos da fala para a escrita } \\
\hline $\begin{array}{c}\text { Desvios decorrentes da } \\
\text { interferência de regras fonológicas } \\
\text { no falar estudado }\end{array}$ & $\begin{array}{c}\text { Desvios decorrentes da interferência } \\
\text { de regras fonológicas variáveis } \\
\text { graduais }\end{array}$ & $\begin{array}{c}\text { Desvios decorrentes da interferência } \\
\text { de regras fonológicas variáveis } \\
\text { descontínuas }\end{array}$ \\
\hline & $\begin{array}{l}\text { Dexa } \\
\text { Cheroso } \\
\text { Descubrir }\end{array}$ & Sorir $(2 \mathrm{x})$ \\
\hline
\end{tabular}

Fonte: Produção de texto anúncio publicitário. Realizada em 09/11/2016 e 22/11/2016. 
No caso das meninas, tivemos ocorrência de desvios em duas categorias: na categoria de desvios provenientes de interferência de regras variáveis graduais, tivemos as palavras "dexa" (deixa) e "cheroso" (cheiroso), que se classificam como monotongação de ditongos decrescentes e a palavra "descubrir" (descobrir), que caracteriza um caso de elevação ou alteamento da vogal média posterior, bastante típico na fala brasileira, principalmente do Sul do país. A elevação da média-alta anterior, /e/ para /i/, também é registrada nos dados, como em "leiti” (leite), “denti” (dente), em posição pós-tônica. Na categoria de desvios decorrentes de regras fonológicas variáveis descontínuas, tivemos a palavra "sorir" (sorrir); nessa categoria podem ser classificados os desvios relacionados à classe social e à oposição rural x urbano, como parece ser o caso dessa palavra.

No corpus, encontramos também a palavra "desadorante" (desodorante), que também classificamos como "outros casos ou casos acidentais", conforme classifica Oliveira (2005), mas que também pode representar um processo fonológico ou metaplasmo.

Graficamente, podemos representar os desvios de representação nasal e representação da sibilante /s/ da seguinte maneira:

Gráfico 01: Desvios de representação da sibilante /s/ e de representação nasal em textos de meninos e meninas:

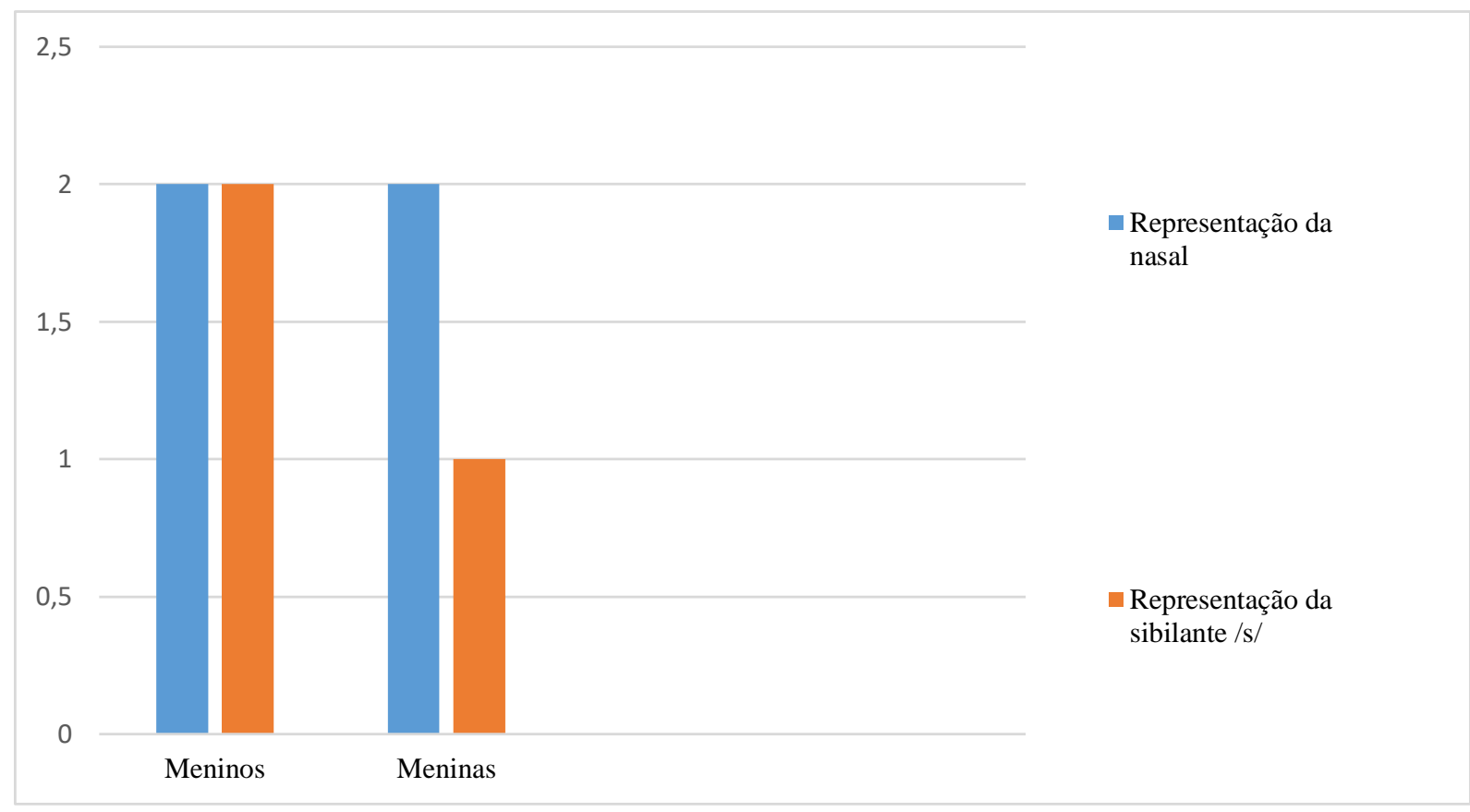

Fonte: Produção de texto anúncio publicitário. Realizada em 09/11/2016 e 22/11/2016.

Tivemos, na produção do anúncio, poucos desvios de representação nasal, apenas 2 duas ocorrências para meninos e 2 ocorrências para meninas. Na representação da sibilante /s/, as ocorrências são ainda menores: apenas 2 casos para meninos e 1 caso para meninas. 
Acreditamos que as meninas tenham apresentado diminuição de desvios de grafia, pois, de acordo com pesquisa realizada com a turma e analisada no capítulo da Metodologia deste trabalho, das 14 meninas em sala, apenas 2 disseram não fazer o dever sempre ou quase sempre. Para os meninos, apenas 6, de 9, afirmaram fazer o dever sempre ou quase sempre.

Como sabemos, não há, em sala de aula, como explorar com profundidade todos os conteúdos, ficando a tarefa de casa responsável por fixá-los. Assim, talvez o fato de as meninas realizarem o dever com mais frequência tenha ajudado também, além do trabalho com a Unidade Didática, na diminuição dos desvios.

Na categoria dos desvios de transposição dos hábitos da fala para a escrita, tivemos poucas ocorrências:

Gráfico 02: Desvios de transposição dos hábitos da fala para a escrita em textos de meninos e meninas:

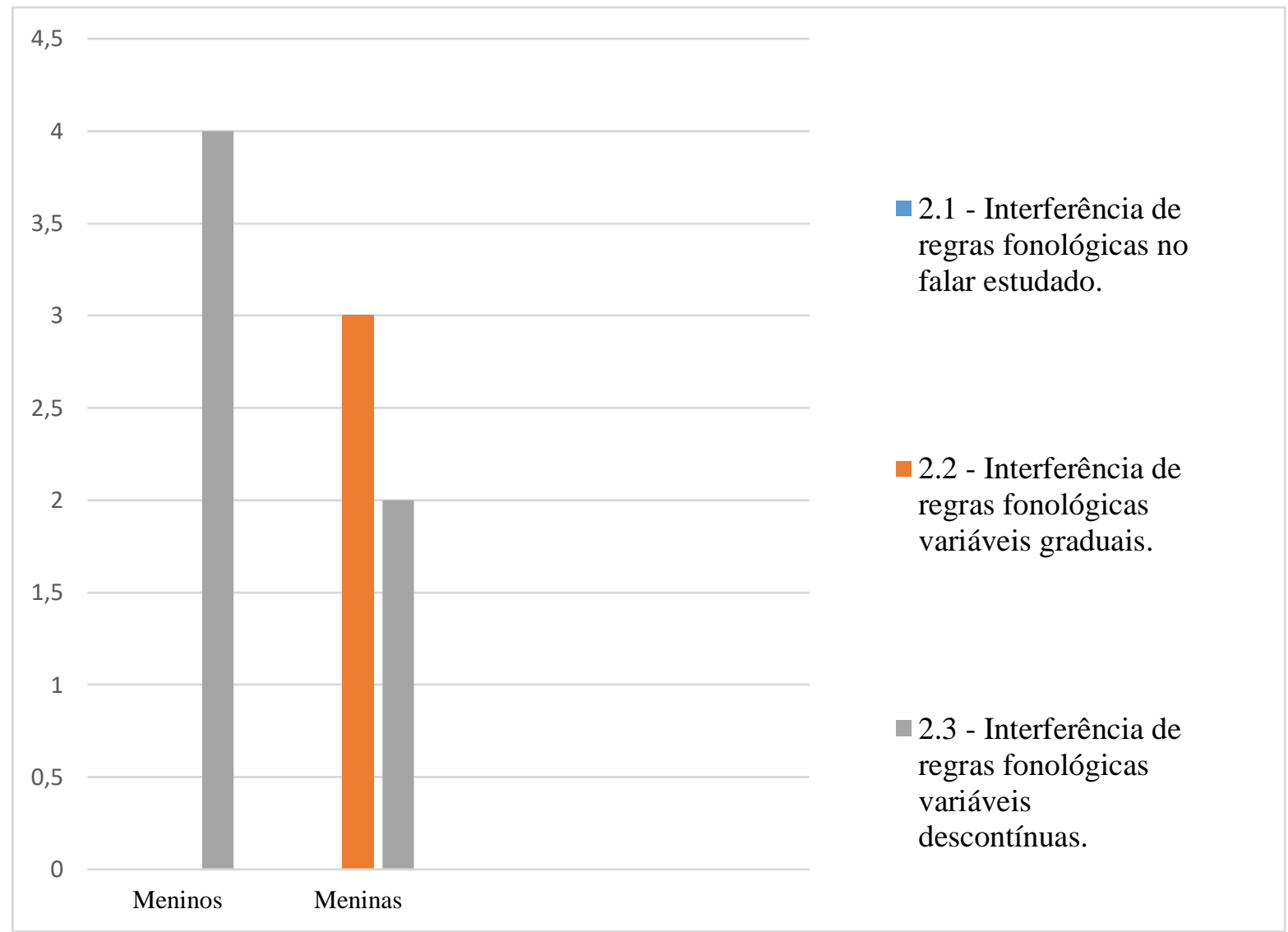

Fonte: Produção de texto anúncio publicitário. Realizada em 09/11/2016 e 22/11/2016.

$\mathrm{Na}$ primeira subcategoria, a dos desvios decorrentes da interferência de regras fonológicas no falar estudado, não tivemos nenhuma ocorrência, nem nos textos de meninos, nem nos textos de meninas. Na segunda subcategoria, a dos desvios decorrentes da interferência de regras fonológicas variáveis graduais, nos textos dos meninos não houve 
nenhuma ocorrência e, nos textos das meninas, houve 4 ocorrências. Na terceira subcategoria, a dos desvios decorrentes da interferência de regras fonológicas variáveis graduais, tivemos 4 ocorrências nos textos dos meninos e 2 ocorrências nos textos das meninas.

A sala de aula na qual realizei a pesquisa era bastante tumultuada e ativa, pois, além de ser o mês de novembro, os alunos e professores haviam acabado de sair de uma greve. Por isso, estavam tendo 6 aulas diárias, inclusive aos sábados. Esses fatores influenciaram na coleta dos dados, pois era difícil controlar a agitação da turma e orientar sobre a atividade que deveriam realizar. Apesar disso, a recepção sempre calorosa da professora regente permitiu a aplicação da Unidade Didática.

A turma na qual trabalhamos apresentou alguns traços no seu comportamento, principalmente entre as meninas. Das 14 meninas que preencheram o questionário, 6 eram repetentes; do total de 9 meninos, 3 eram repetentes. Proporcionalmente, $42,85 \%$ das meninas são repetentes, contra 33,33\% dos meninos. Observamos que, por não estarem na mesma faixa etária da turma, havia um comportamento diferente ao realizar as atividades, além das deficiências de conteúdos, que se destacava. Conforme os dados já colocados acima, 2 tinham 15 ou mais, enquanto no grupo dos meninos a idade máxima era a de 13 anos.

Além disso, o comportamento das meninas era um pouco relutante em colaborar com as atividades. Porém, apesar de aparentemente prestarem menos atenção à explicação e às atividades, foi possível, com uma didática específica, desenvolver um trabalho produtivo, tendo levado a resultados positivos.

Ademais, os alunos compreenderam a função do gênero anúncio publicitário, procurando fazer anúncios atrativos e coloridos, combinando texto e imagem, e escrevendo frases curtas e positivas a respeito do produto. Muitos alunos procuraram despertar a necessidade do consumidor, em frases como "você vai ficar ótimo com ele", "você vai atrair garotas", entre outros.

\section{Conclusões}

Observando os dados gerados, podemos observar que nossos objetivos foram alcançados, pois pretendíamos levar os alunos a compreenderem as regularidades e as irregularidades ortográficas da língua portuguesa; a reconhecerem as representações grafemáticas de uma mesma unidade sonora e a identificarem as principais características e elementos do gênero anúncio publicitário. Tais objetivos, conforme os dados revelam, foram atingidos, considerando que em apenas uma das categorias não houve mudança de número de 
ocorrências, em duas categorias tivemos diminuição de ocorrências e em três tivemos completa eliminação de ocorrências.

Por meio dos dados, é possível observar que um trabalho sistematizado com a variação linguística em sala é necessário, considerando a modalidade oral e escrita da língua.

As coletas de dados que realizamos junto à escola demonstraram que os alunos apresentam desvios e dúvidas de registro ortográfico, muitas vezes, por não conhecerem as regras da grafia do português e, em consequência, acabam por não as dominar na escrita.

Após o trabalho com a Unidade Didática, observamos que um trabalho sistematizado com a ortografia é não só possível, mas necessário. Foi possível trabalhar com as principais dificuldades ortográficas dos alunos, e por meio de atividades específicas, as diminuímos, ou, em alguns casos, as eliminamos.

Assim, concluímos que um trabalho, como o que foi realizado, é necessário e possível, pois, com sistematização e retomada das regras, os alunos compreenderam de forma mais completa as irregularidades do código. Consideramos, ainda, que há limites neste trabalho, levando em conta o tempo destinado para a realização do Mestrado. Investigações mais sistemáticas são, sem dúvida, necessárias.

\section{Referências bibliográficas}

BORTONI-RICARDO, Stella Maris. Nós chegemu na escola, e agora? São Paulo: Parábola, 2006. (Obra completa)

BUSSE, Sanimar. Língua portuguesa, diversidade e ensino: uma análise de contextos multilíngues. In: Anais... Goiânia: Simpósio Mundial de Estudos de Língua Portuguesa, 4, 2013, p. 191-197. (Trabalho em Anais de Congresso)

MORAIS, Artur Gomes de. Ortografia: este peculiar objeto de conhecimento. In: MORAIS, Artur Gomes de. O Aprendizado da Ortografia. Belo Horizonte: Autêntica, 2007. p. 31-37 (Capítulo de livro) 